\title{
EXPERIENCIA DE LA TECNOLOGÍA DE PERCEPCIÓN REMOTA PARA LA ELABORACIÓN DEL MOSAICO DE IMÁGENES DE SATÉLITE LANDSAT TM EN LA SELVA BAJA DE LA AMAZONÍA PERUANA
}

\author{
León Bendayán Acosta ${ }^{1}$, José Sanjurjo Vílchez ${ }^{1}$, Risto Kalliola ${ }^{2}$ y Fernando Rodríguez Achung ${ }^{3}$
}

\section{RESUMEN}

El presente trabajo tiene como objetivo mostrar la experiencia de aplicación de la tecnología de percepción remota para la elaboración de un mosaico de imágenes de satélite Landsat TM que cubra la selva baja de la Amazonía peruana. Para este mosaico fueron utilizadas 42 escenas de imágenes que cubren todo el ámbito de la selva baja. Con la percepción remota se colecta información a distancia a través de sensores que registran la radiación electromagnética emitida o reflejada por los elementos o cuerpos que cubren la superficie de la tierra. Cada cobertura terrestre emite o refleja energía en una longitud de onda específica; esta energía reflejada que llega al sensor es transformada a valores numéricos, para luego ser procesada en las estaciones terrestres y ser presentada a los usuarios como imágenes digitales. Para facilitar la elaboración del mosaico de la selva baja del Perú fue necesario realizar algunos ajustes previos, como el reconocimiento de anomalías en las imágenes (nubes, ruidos electromagnéticos, etc.); las correcciones cosméticas, que sirvieron para corregir las líneas faltantes; el ordenamiento de bandas, que nos permitió seleccionar las bandas necesarias; y la georeferenciación de las imágenes, que nos permitió ubicar la imagen en su verdadera dimensión espacial con vínculo en un sistema de proyección. Se mejoró la calidad de presentación del mosaico, y para esto fueron aplicados algunos procedimientos como la interpolación, que consiste en eliminar la gradiente interna que se produce debido probablemente a la influencia atmosférica asimétrica en el área cubierta, y la armonización de histogramas por coeficientes y por diferencia, que nos permitió corregir la proporcionalidad de los niveles digitales entre imágenes, produciendo superficies sin límites muy contrastantes. Los resultados derivados del mosaico han permitido enfatizar ciertas temáticas; producto de ello se elaboró el mapa de diversidad de vegetación, y el mapa de unidades ambientales, ambos en su versión preliminar. También se puede decir que el mosaico y los productos derivados del mismo son como una ventana de apoyo para generación de conocimientos en beneficio de nuestra región amazónica.

Palabras clave: Armonización de histogramas por coeficientes y por diferencia, correcciones cosméticas, georeferenciación, interpolación, Landsat TM, mapa de diversidad de vegetación, mapa de unidades ambientales, mosaico de imágenes de satélite, ordenamiento de bandas, percepción remota, procesamiento de imágenes.

\footnotetext{
ABSTRACT

This work aims to show the experience of applying remote perception technology, using Landsat TM satellite images to draw a mosaic covering the lowlands of the Peruvian Amazon. For the mosaic, 42 satellite images covering the Peruvian lowland forests were used. Through remote sensing, information can be collected from a distance by sensors that register the electromagnetic radiation emitted or reflected by elements or objects covering the surface of the Earth. Each ground object emits or reflects energy in a specific wavelength; on arrival at the

1 Proyecto Diversidad Biológica de la Amazonía Peruana - BIODAMAZ, Perú - Finlandia. Av. Abelardo Quiñones km 2.5, Iquitos, Perú. Correo electrónico: biodamaz@iiap.org.pe / Centro de Información de la Amazonía Peruana, Instituto de Investigaciones de la Amazonía Peruana - IIAP. Av. Abelardo Quiñones km 2.5, Iquitos, Perú.

2 Proyecto Diversidad Biológica de la Amazonía Peruana - BIODAMAZ, Perú - Finlandia. Av. Abelardo Quiñones km 2.5, Iquitos, Perú / Departamento de Geografía, Universidad de Turku, 20014 Turku, Finlandia. Correo electrónico: biodamaz@iiap.org.pe

3 Proyecto Diversidad Biológica de la Amazonía Peruana - BIODAMAZ, Perú - Finlandia. Av. Abelardo Quiñones km 2.5, Iquitos, Perú / Programa de Ordenamiento Ambiental - POA, Instituto de Investigaciones de la Amazonía Peruana - IIAP. Av. Abelardo Quiñones km 2.5, Iquitos, Perú. Correo electrónico: biodamaz@iiap.org.pe
} 
sensor this reflected energy is transformed into numerical values that can then be processed in ground stations and presented to users as digital images. To facilitate the creation of this mosaic of the Peruvian Amazon lowland it was necessary to make some prior adjustments: the recognition of anomalies in the images (clouds, noise, etc.); cosmetic corrections, which served to correct the missing lines; the ordination of bands, allowing us to select the necessary bands; and the geo-referencing of the images, which allowed us to locate the image in its true space dimension with a link to a projection system. The presentation quality of the mosaic was improved by applying certain procedures such as interpolation. This procedure consists of eliminating the internal gradient that is most likely caused by the asymmetric atmospheric influence in the covered area. Additionally, the harmonization of histograms by coefficients and by difference allowed us to correct the proportionality of the digital levels between images, resulting in surfaces without very contrasting limits. The products deriving from the mosaic have enabled us to emphasize certain themes and as a result the preliminary versions of the vegetation diversity and environmental units maps were produced. It can also be said that the mosaic and products deriving from it will support a generation of knowledge that will benefit the Amazon region.

Key words: Cosmetic corrections, geo-referencing, harmonization of histograms by coefficients, image processing, interpolation, Landsat TM, map of environmental units, map of vegetation diversity, ordination of bands, remote sensing, satellite image mosaic.

\section{INTRODUCCIÓN}

Con la idea de llegar más allá de lo que pueden ver nuestros ojos nace la tecnología de la percepción remota, y con esto la necesidad de poder ver en conjunto el espacio que nos rodea. Por ello, en el marco del Convenio Perú - Finlandia, proyecto Diversidad Biológica de la Amazonía Peruana - BIODAMAZ, Perú - Finlandia, se ha elaborado un mosaico de imágenes Landsat TM que cubre la selva baja de la Amazonía peruana.

Esta iniciativa es producto del esfuerzo y la interacción de instituciones bastante diversas, principalmente de la contraparte nacional del proyecto BIODAMAZ, el Instituto de Investigaciones de la Amazonía Peruana (IIAP), y la institución colaboradora, la Universidad Nacional de la Amazonía Peruana (UNAP), y el equipo de asistencia técnica del consorcio finlandés del proyecto BIODAMAZ, la empresa de consultorías ambientales, Biota BD Oy, y la Universidad de Turku.

Producto de esta interacción nace el interés de elaborar un mosaico de imágenes de satélite que cubra la selva baja de la Amazonía peruana; es decir, los bosques que se encuentran localizados desde los 600 m.s.n.m hacia abajo (Tarazona, 1999). Con este insumo ha sido elaborado el mapa de diversidad de vegetación y el mapa de unidades ambientales; como instrumentos de apoyo para el proceso de Zonificación Ecológica Económica (ZEE).

El presente trabajo tiene como objetivo mostrar la experiencia de la aplicación de la tecnología de la percepción remota para la elaboración de un mosaico de imágenes de satélite Landsat TM que cubra la selva baja de la Amazonía peruana. Para este mosaico fueron utilizadas 42 escenas de imágenes que cubren todo el ámbito de la selva baja. Con la percepción remota se colecta información a distancia a través de sensores que registran la radiación electromagnética emitida o reflejada por los elementos o cuerpos que cubren la superficie de la tierra. Cada cobertura terrestre emite o refleja energía en una longitud de onda específica; esta energía reflejada que llega al sensor es transformada a valores numéricos, para luego ser procesada en las estaciones terrestres y ser presentada a los usuarios como imágenes digitales (Chuvieco, 1996).

En términos generales, un mosaico puede ser entendido como un conjunto de dos o más imágenes enlazadas entre sí en forma contigua, cuya elaboración comprende diversas operaciones técnicas, tales como la corrección geométrica, corrección radiométrica, interpolaciones, armonización, etc., que van a permitir una mejor presentación de la imagen y facilitar su interpretación.

Los sistemas de percepción remota poseen en la actualidad un alto grado de desarrollo, y están equipados con un conjunto de herramientas que, aplicados adecuadamente, permiten la obtención de datos y la producción de información que puesta a disposición de los agentes que tienen que ver con las decisiones, incrementan su 
conocimiento sobre los recursos naturales y el medio ambiente. En la actualidad la tecnología de los sensores remotos ha alcanzado grandes avances, permitiéndonos la obtención de información a través de imágenes digitales de mediana y alta resolución en un menor tiempo, y haciendo posible el monitoreo permanente de los eventos que ocurren en el medio ambiente.

Desde el punto de vista ambiental la tecnología de la percepción remota ha demostrado ser una herramienta muy efectiva para la determinación de variables ambientales, tales como áreas contaminadas por presencia de hidrocarburos, tipos de vegetación, condición del agua, tipos de suelos, y procesos de ocupación territorial, entre otros (Ellis et al., 2001; Morella, 2002).

Las imágenes Landsat TM son muy aptas para estudios de gran escala. Sin embargo, para estudios detallados será necesario algún otro medio de percepción remota de mayor resolución espacial. Este mosaico será utilizado para fines de planificación del uso de la tierra, y para la determinación de patrones de reflectancia que nos permitan identificar diferentes coberturas en la superficie terrestre.

El propósito de este artículo es poner en conocimiento de la comunidad científica en general, técnicos, estudiantes y otros usuarios, la metodología que se aplicó para la elaboración del mosaico de imágenes Landsat TM de la selva baja peruana en el proyecto BIODAMAZ, Perú - Finlandia.

\section{MATERIAL Y MÉTODO}

En este trabajo fueron utilizadas 42 escenas de imágenes Landsat TM que cubren la selva baja de la Amazonía peruana (Figura 1); el software utilizado fue el ERDAS IMAGINE. La metodología utilizada para el trabajo se resume en la Figura 2.

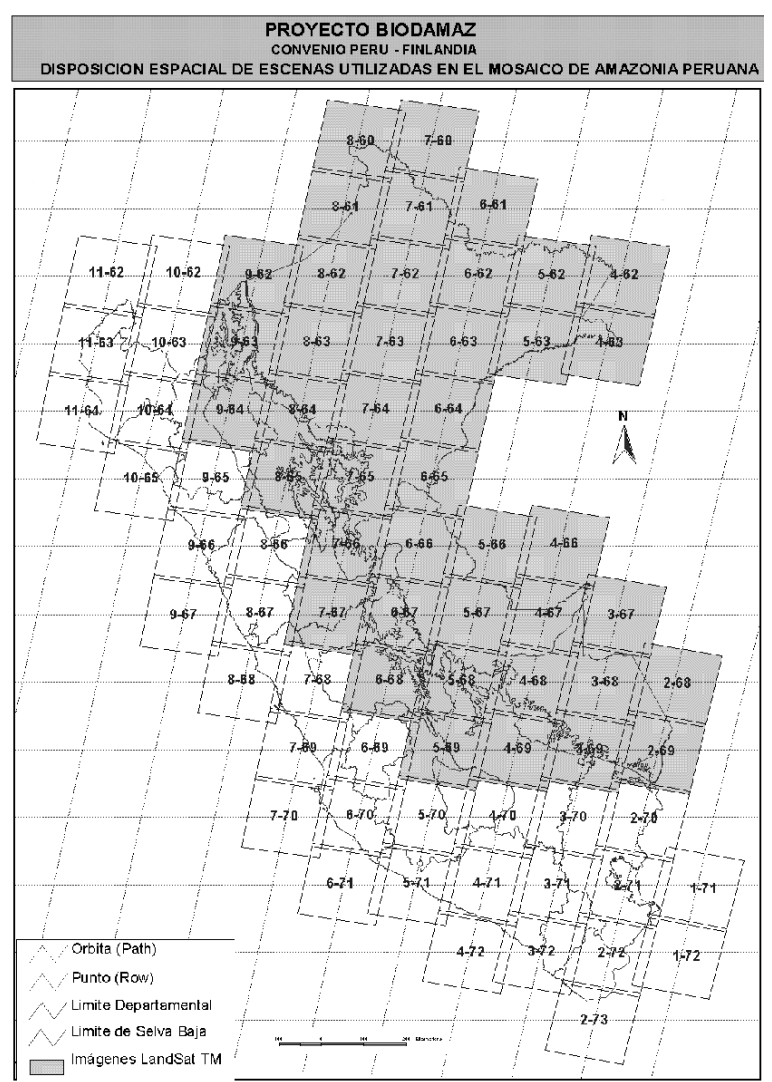

Figura 1. Imágenes Landsat TM cubriendo área del proyecto. Fuente: IIAP-BIODAMAZ. 


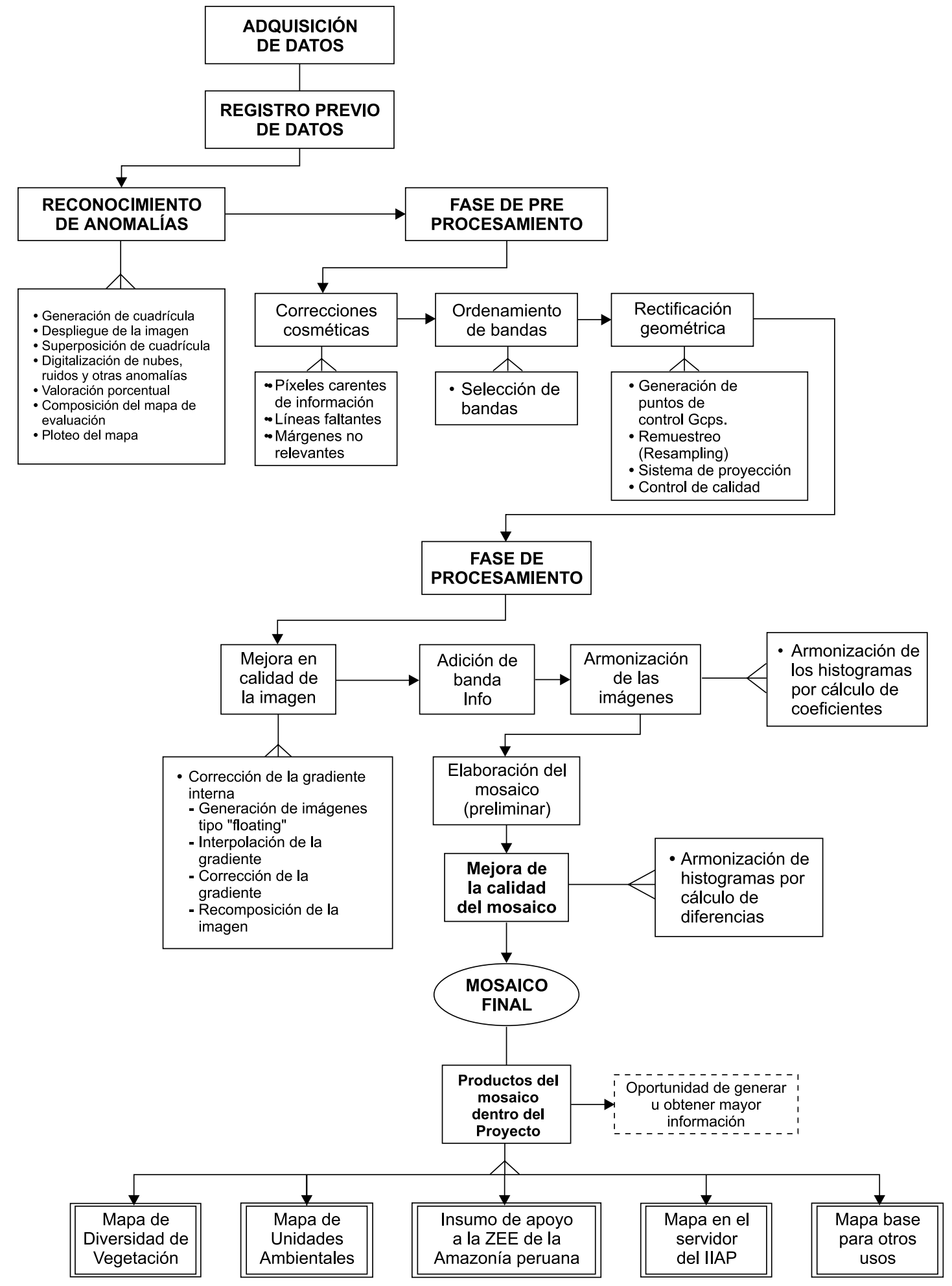

Figura 2. Metodología utilizada en el proyecto. 


\subsection{Adquisición y registro previo de datos}

Como indica la metodología esquematizada, todo este proceso comienza con la recepción de las imágenes en el proyecto, como parte del compromiso de la cooperación finlandesa; posteriormente se hace un registro previo a la información satelital. Este es un paso muy importante, ya que permite optimizar el uso de las imágenes e identificar las anomalías presentes, como presencia de nubes, ruidos, etc., y tomar decisiones sobre la utilidad de las mismas.

\subsection{Fase de pre-procesamiento}

Antes del procesamiento digital, las imágenes fueron sometidas a una fase de pre-procesamiento, que consistió en el desarrollo de algunos procesos básicos: 1) las correcciones cosméticas que permiten corregir problemas como "sal y pimienta", es decir, píxeles carentes de información, líneas faltantes y márgenes no relevantes en las imágenes; 2) el ordenamiento de bandas que nos permitió seleccionar aquellas bandas que satisfacen las necesidades del proyecto: por ejemplo, en una escena con siete bandas, en la cual la banda seis resulta irrelevante, será necesario separarla; 3 ) por último, la rectificación o corrección geométrica, que nos permite referenciar o vincular la imagen a un sistema de proyección, utilizando como referencia las cartas nacionales a escala de 1:100 000, producidas por el Instituto Geográfico Nacional. Este proceso es el que demanda más tiempo de dedicación, debido a lo laborioso de su procedimiento, ya que consiste en localizar puntos comunes o puntos de control entre las imágenes y el mapa de referencia (cartas nacionales), y extraer los valores de coordenadas de la carta, para luego ser registrados en el sistema como valores GCP (Ground Control Points). (Kalliola, 2001).

En cuanto a la localización de los puntos de referencia, algunos autores recomiendan que sean puntos claramente identificables en la imagen y en el mapa de referencia, sobre todo si se trata de rasgos producidos por la acción del hombre, tales como cruces de carreteras, pistas de aterrizaje, edificaciones, etc. No es conveniente señalar puntos en las riberas de los ríos, pues diversos efectos naturales modificarían la ubicación de los mismos (Gonzáles, 1995). Sin embargo, las consideraciones en cuanto a la elección de puntos referenciales invariables son poco aplicables en la selva baja de la Amazonía peruana, debido a que estas áreas generalmente se encuentran en zonas específicas, como por ejemplo: Iquitos (carretera Iquitos - Nauta), Aguaytía (carretera Federico Basadre), Madre de Díos (carretera Cuzco - Puerto Maldonado - Iñapari), Yurimaguas (vía hacia Tarapoto), etc. Lo mismo sucede con respecto a los centros poblados, puesto que debido a la poca densidad poblacional y a la resolución de las imágenes utilizada, esta referencia se circunscribe solo a ciudades principales como Iquitos, Pucallpa, Puerto Maldonado y Yurimaguas.

Sin embargo, en el proyecto se decidió utilizar la red hídrica en las áreas donde no sea posible ubicar puntos referenciales de poca variabilidad, teniendo en consideración aspectos como las confluencias de los ríos, las quebradas y la dinámica fluvial.

Se decidió en el proyecto que el sistema de proyección estaría enmarcado dentro de los sistemas más usuales para la zona de trabajo, con el objeto de compatibilizar la información resultante, con la información generada a nivel del país, determinándose lo siguiente: Esferoide WGS84, Datum horizontal WGS84, Proyección UTM y Zona 18 Sur, fundamentalmente porque son parámetros más usuales por el Instituto Geográfico Nacional del Perú. Cabe recalcar que el Perú se ubica en tres zonas geográficas, correspondientes a los números 17, 18 y 19 (Figura 3); tal fenómeno no permite la secuencia espacial de los elementos geográficos cuando se georeferencian, por lo que fue necesario elegir solo una zona de proyección a fin de que exista continuidad entre imágenes o escenas. 


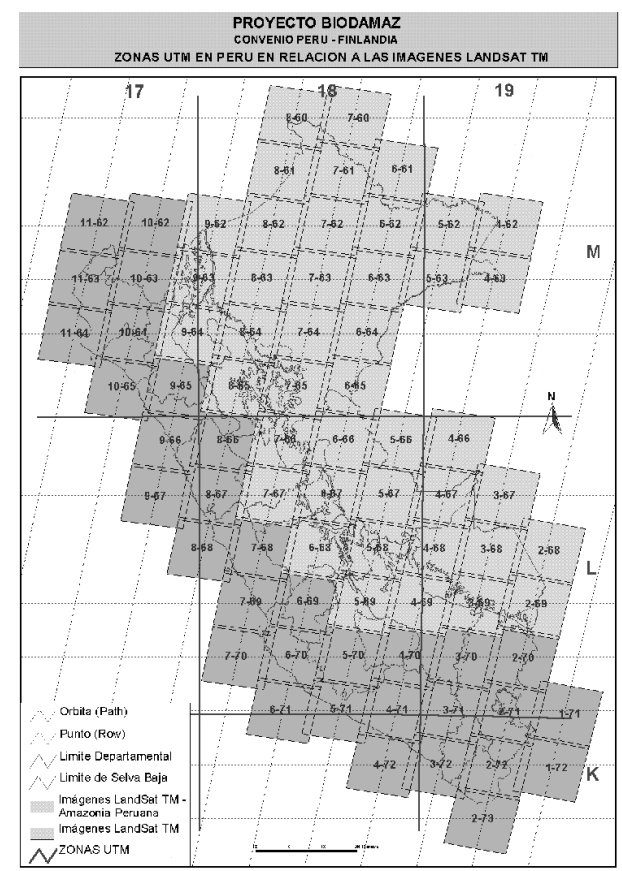

Figura 3. Zonas UTM en Perú. Fuente: IIAP-BIODAMAZ.

Posteriormente al proceso de georeferenciación se procedió a realizar el control de calidad, el cual consistió en primer lugar en la digitalización manual de los rasgos geográficos presentes en la carta nacional y en la imagen digital, con la finalidad de crear un archivo vectorial para luego ser superpuesto a dicha imagen, y de esta manera verificar si existe, o no, desplazamiento de la imagen corregida (Figura 4). Este proceso es importante, pues nos permite garantizar que la imagen georeferenciada posee características de precisión y exactitud.

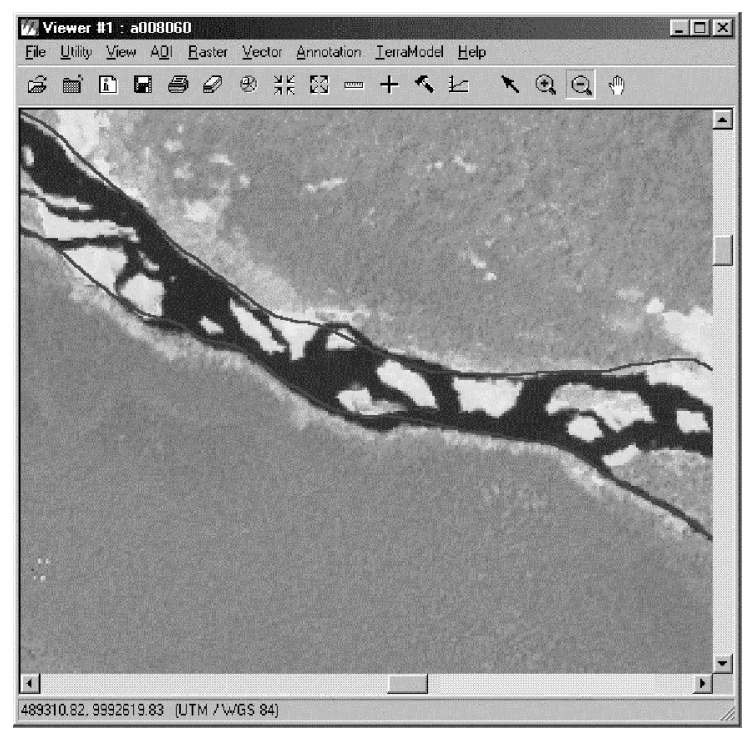

Figura 4. Imagen con vector. 
Una de las limitantes para el manejo del mosaico en los ordenadores fue el volumen de información que agrupa; y esto depende del número de escenas consideradas, número de bandas y del tamaño del píxel propuesto en el proyecto. En tal sentido se realizó una prueba de reproyección de las imágenes con ERDAS, usando diferentes tamaños de píxel ( 30 x 30, 50 x 50 y 100 x 100), con el objeto de calcular el volumen de información a ser manejado en el mosaico. Como consecuencia de este ensayo, se optó por el tamaño de píxel 50 x 50 (Cuadro 1), ya que nos permitió reducir significativamente los tiempos de procesamiento y del espacio, así como también los efectos sobre el paisaje, que fueron mínimos.

Cuadro 1. Cálculo de volumen de información a ser manejado en el mosaico, utilizando tamaños diferentes de píxel.

\begin{tabular}{cccccc}
\hline & & & & \multicolumn{2}{c}{ Espacio (KB) } \\
\cline { 5 - 6 } Tamaño de píxel & Filas & Columnas & Bandas & Calculado & Observado \\
\hline $30 \times 30$ & 7895 & 8679 & 6 & 411124 & 406147 \\
$50 \times 50$ & 4737 & 5208 & 6 & 177626 & 151690 \\
$100 \times 100$ & 2369 & 2605 & 6 & 37027 & 37548 \\
$250 \times 250$ & 948 & 1042 & 6 & 5927 & 6169 \\
$500 \times 500$ & 475 & 522 & 6 & 1487 & 1762 \\
$750 \times 750$ & 317 & 348 & 6 & 661 & 750 \\
\hline
\end{tabular}

\subsection{Fase de procesamiento}

La fase de procesamiento empieza con la mejora de la calidad de las imágenes; en el caso particular del proyecto BIODAMAZ fueron identificados dos procesos principales, la gradiente interna y la correspondencia de histogramas (Kalliola, 2001). La gradiente interna está relacionada con la reflectancia bidireccional (BDRF), que es un fenómeno causado por el ángulo de la luz solar en relación con las características de los gases atmosféricos. Este fenómeno se manifiesta en una desigual iluminación de la imagen, que presenta una tendencia gradual de oscuridad que va en dirección este - oeste (Figura 5).

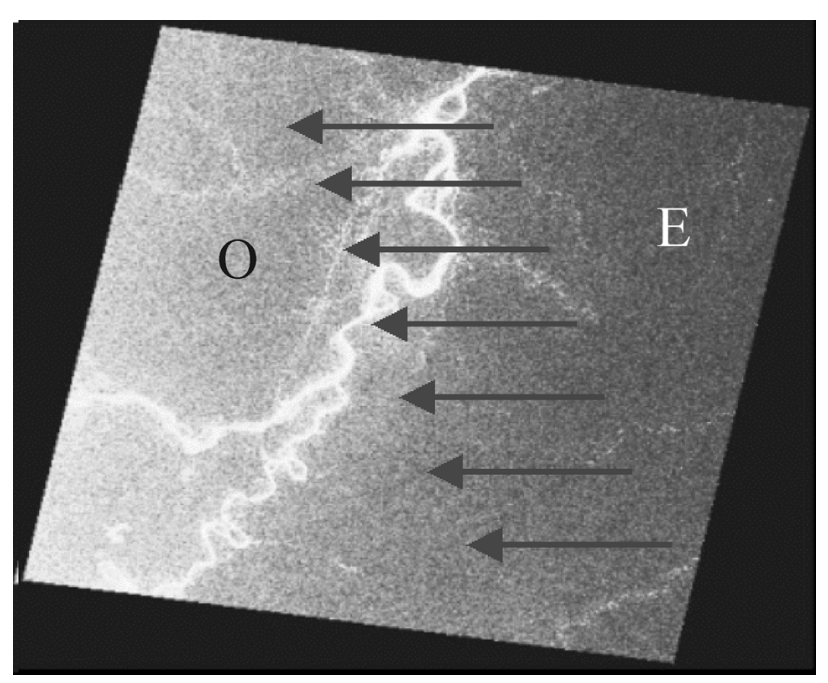

Figura 5. Gradiente interna en una imagen Landsat TM de la zona de Iquitos. 
La corrección de la gradiente por interpolación es un proceso que se fundamenta en la estimación de los valores desconocidos de un fenómeno en particular, en función a valores conocidos u obtenidos en el campo; es decir, se muestrean puntos en la imagen con la finalidad de crear una superficie correspondiente a la gradiente de cada escena y por cada banda en particular, pretendiendo distribuir el valor de los niveles digitales a través de toda la imagen. Este procedimiento consiste de varias fases, siendo la primera la generación de imágenes tipo "floating". Para ello se descompuso la imagen en sus seis bandas, mediante un modelo específico creado en ERDAS “a_crear_6_ims_float_10.gmd”, generando datos tipo "float double” (Figura 6). Para almacenar los resultados de esta fase fue necesario crear una carpeta denominada Temporal.

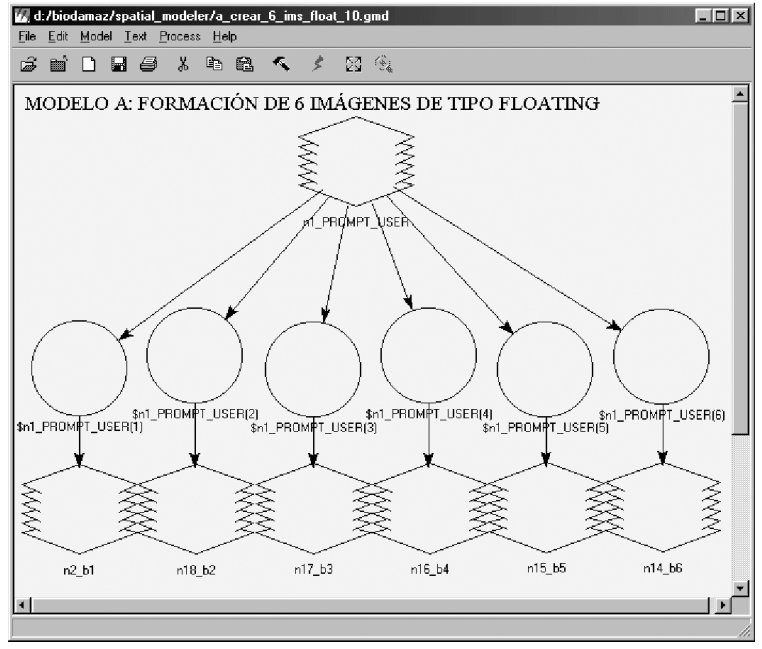

Figura 6. Modelo para generar seis imágenes tipo floating.

Una vez conseguidas las imágenes de tipo floating fue necesario interpolar la gradiente. Para esto se creo una carpeta con el nombre de Grad_Interpo, donde se almacenaron los resultados de esta fase. Se desplegó la imagen producto de la carpeta Temporal (por ejemplo, b1.img), y se procedió a delimitar con la herramienta AOI de ERDAS el área de interés (area of interest), para luego proceder a digitalizar alrededor de 100 puntos distribuidos proporcionalmente sobre el área seleccionada, teniendo la precaución de no incluir nubes, cuerpos de agua (ríos, lagos), pantanos y zonas deforestadas (Figura 7). Este proceso da como resultado una imagen con franjas, cuya distribución está en función de la forma general de la gradiente (Figura 8).

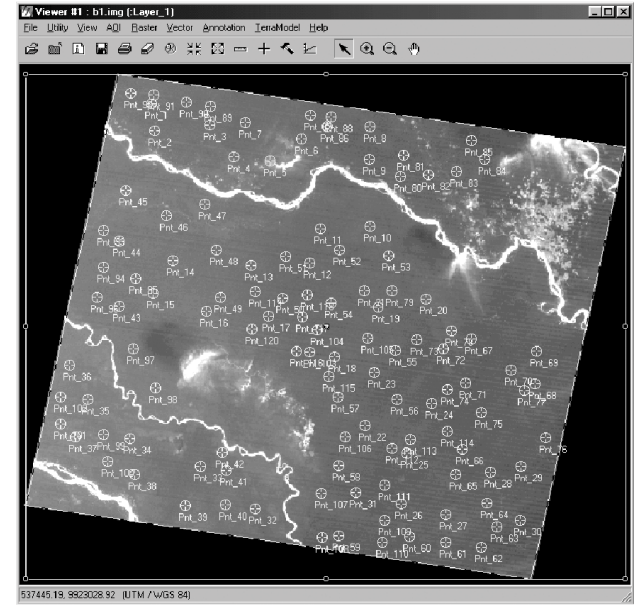

Figura 7. Digitalización de los puntos.

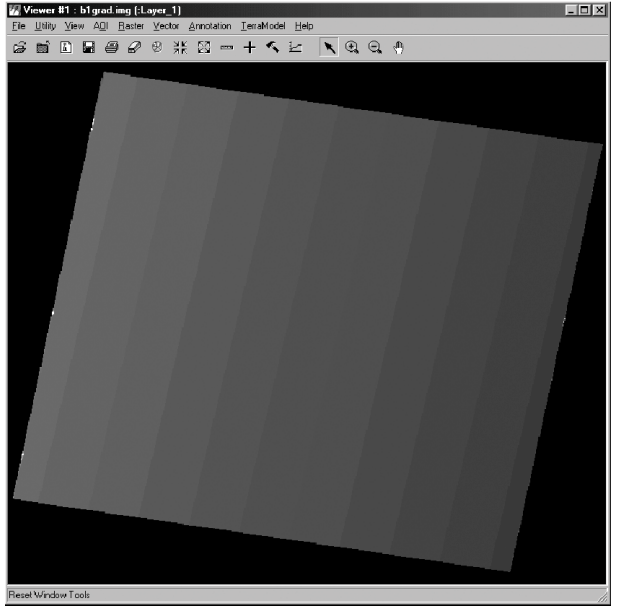

Figura 8. Imagen resultado de la interpolación. 
Se creó la carpeta (por ejemplo, Grad_Corr) para almacenar los resultados de la corrección de la gradiente; para esto se utilizó el modelo "b_corregir_gradiente_10.gmd" (Figura 9). Este modelo utiliza las imágenes interpoladas y genera coberturas random, eliminando las fajas generadas en la interpolación. También excluye los valores no deseados y reajusta los valores válidos; es decir, corrige las bandas originales.

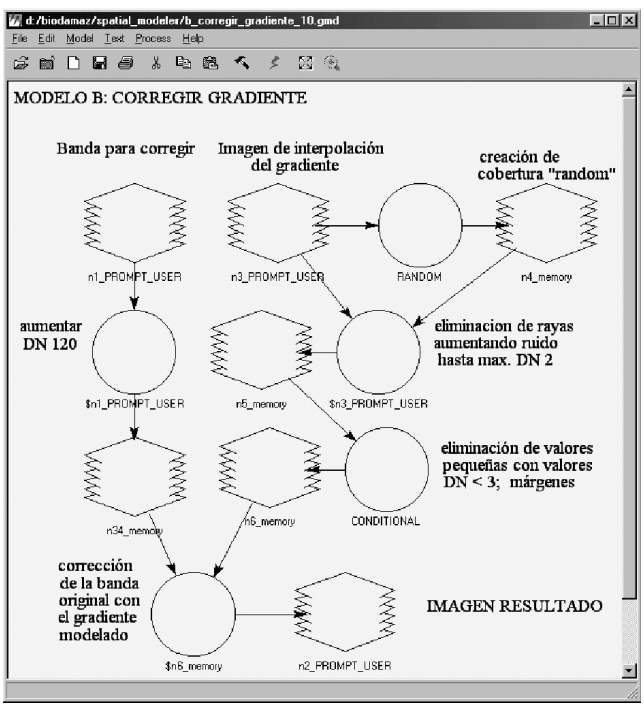

Figura 9. Modelo para corregir gradientes.

Después de la corrección se procedió a recomponer la imagen; para este caso particular se utilizó el modelo “c_crear_im_corregida_10.gmd" (Figura 10), cuya particularidad es agrupar las bandas corregidas en una imagen con seis bandas. Se creó una carpeta (por ejemplo, Grad_Corr_Recompo), en donde fueron almacenados los resultados de este proceso.

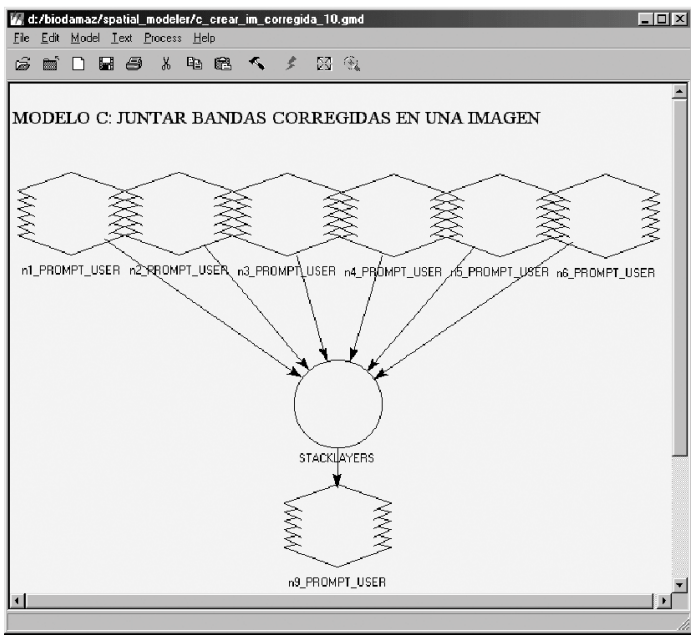

Figura 10. Modelo que une las bandas.

La adición de la banda de información tiene por finalidad identificar cada escena que conforma el mosaico, y consiste en agregar a cada imagen recompuesta una banda adicional denominada banda siete o banda info, en donde se registra el código que identifica a la escena. Para nuestro caso se utilizó el modelo "e_adiciona_layer_info.gmd", el cual genera una banda cuyos píxeles contienen el código de la escena (Figura 11). Se creó una carpeta denominada (por ejemplo, Grad_Corr_Layer_Info), en donde fueron guardadas todas las escenas codificadas. 


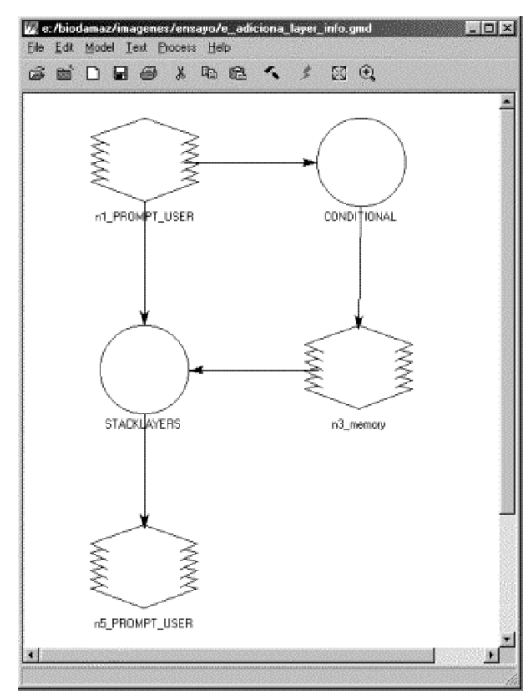

Figura 11. Modelo de adición de banda info.

Para generar un mosaico de alta calidad y sin diferencias contrastantes fue necesario armonizar los histogramas de las imágenes. Este proceso consiste en juntar las imágenes registradas en lo posible en las mismas fechas, con la finalidad de delimitar en la zona de traslape, con la herramienta de AOI, áreas que representan cobertura de tierra uniforme sin presencia de nubes, cuerpos de agua, áreas deforestadas, relieve accidentado, zonas con problemas de drenaje, etc. Es decir, los factores que pueden modificar o influenciar en los resultados.

Para establecer las relaciones de correspondencia entre las dos imágenes fueron considerados dos aspectos: imagen pasivo, que es la imagen que presenta la menor cobertura de nubes, sombras y otros aspectos no deseados, y la imagen candidato, que es la imagen a ser corregida.

Fueron aplicados dos métodos principales para calcular los valores estadísticos de los píxeles en el área de interés: el método por cálculo de coeficientes y el método por cálculo de diferencias.

El método por cálculo de coeficientes consiste en extraer, de cada banda de la imagen pasivo y candidato, la información del promedio estadístico del área de interés delimitado por AOI. Esta información se registró en una tabla de Excel (Coef_para_harmo_imgs.xls), en donde los valores positivos indican que los NDs (niveles digitales) de la banda serán incrementados según el valor del coeficiente; en cambio, si los valores de los NDs son negativos, serán reducidos según la cantidad presentada (Figuras 12 y 13).

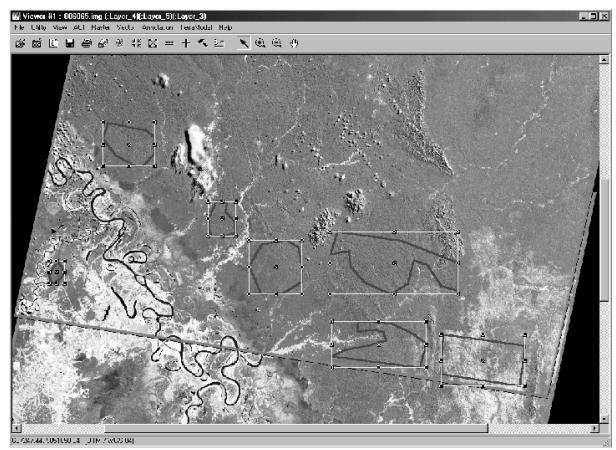

Figura 12. Definición de áreas de interés.

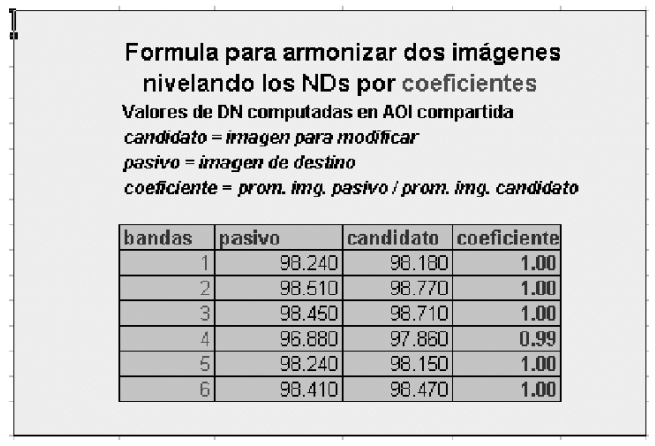

Figura 13. Tabla de coeficientes. 
Para la armonización se utilizó el modelo “d_harmonización_aoi_10_6bandas.gmd”. Este modelo utiliza el coeficiente definido por cada banda para multiplicar los valores de los píxeles de la imagen candidato, de modo que sean proporcionales a la imagen candidato. Posteriormente a este proceso se desplegó las imágenes pasivo y candidato en una misma vista, y se hizo combinaciones de bandas, se aplicó algunas técnicas para resaltar el contraste (Ecualización del histograma o Re-escalamiento de los histogramas y tablas look-up), con la finalidad de comparar si la luminosidad es proporcional en ambas imágenes y poder generar el mosaico.

Una vez obtenidas las imágenes armonizadas, se elaboró el MOSAICO, llevando a cabo varios procesos con ERDAS, desde la adición de las imágenes en la ventana de Mosaic Tool hasta correr el proceso de elaboración del mosaico en la ventana de diálogo Run Mosaic; esta operación nos permitió que las imágenes se dispongan en forma correlativa una tras otra; es decir, formando una especie de rompecabezas. Cabe recalcar que para que la superposición sea lo mejor posible se ha tenido en consideración algunos aspectos, como antigüedad de la imagen y presencia de nubes, en el caso que hubiera. Es decir, las imágenes antiguas irán debajo de la más actual; y si por algún caso la imagen antigua no presenta nubes en el área de traslape y la actual sí, el criterio fue dar preferencia a la antigua.

La ejecución de los anteriores procesos nos permite suponer que los píxeles de las imágenes armonizadas se encuentran con valores proporcionales, lo que nos permitirá elaborar un mosaico con una presentación de calidad. Sin embargo, al verificar en su totalidad el mosaico se encontró que hay ciertos sectores que no presentan esa homogeneidad supuesta, resaltándose los límites entre imágenes vecinas y los valores digitales mayores o menores con respecto a las imágenes vecinas (Figura 14).

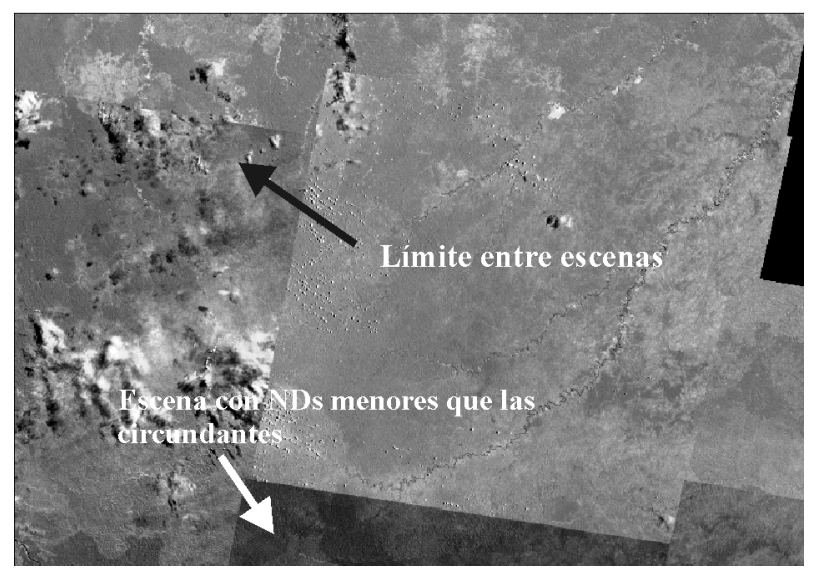

Figura 14. Ventana del mosaico en donde se visualiza las diferencias encontradas en las imágenes armonizadas.

Para corregir estas diferencias fue necesario desarrollar la metodología de armonización de histogramas por cálculo de diferencias, la cual se fundamenta en el incremento o decremento de los NDs de las escenas elegidas como candidato. Este proceso es parecido a la armonización por cálculo de coeficientes; la diferencia radica solamente en que los valores digitales de la imagen candidato se modifican según los valores digitales de la imagen pasivo, aplicando los siguientes criterios:

- Aplicar un decremento en los NDs de la escena candidato cuando estos valores sean mayores a los correspondientes de la escena pasivo.

- Aplicar un incremento en los NDs de la escena candidato cuando estos valores sean menores a los correspondientes de la escena pasivo.

Estas operaciones se desarrollaron sobre cada una de las bandas de las imágenes que presentan los problemas, y se empezó primeramente con definir las áreas de interés en la imagen pasivo haciendo uso de la herramienta de AOI de ERDAS; luego, se calculó las estadísticas del valor promedio por banda del área de interés de la 
imagen pasivo. Una vez registrados los valores estadísticos se procedió a retirar o guardar estas áreas de interés, con la finalidad de crear nuevas áreas en zonas similares en la imagen candidato, teniendo cuidado de no delimitar áreas con ríos, nubes u otros elementos no deseados. Posteriormente, fueron calculadas las estadísticas y se registró estos valores en un formato usado para este fin.

Se calculó los coeficientes de armonización haciendo uso de la tabla (Difer_para_armo_imgs.xls), en donde se incorporó los valores estadísticos del promedio y se calculó los coeficientes por diferencia (Figura 14). Posteriormente, fueron armonizadas las imágenes haciendo uso del modelo (f_armonización_mosaico_diferencias.gmd), el cual tiene la propiedad de descomponer la imagen en sus siete bandas, recalcular los valores de los píxeles de la escena candidato, lo cual lo identifica a través de la banda info (Figura 15).

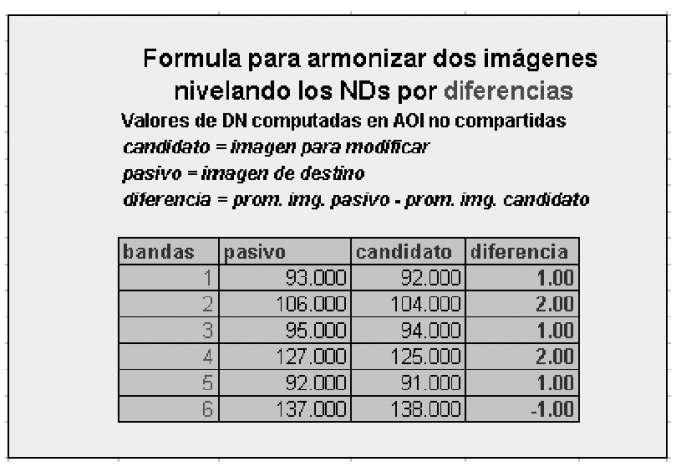

Figura 15. Fórmula para calcular las diferencias.

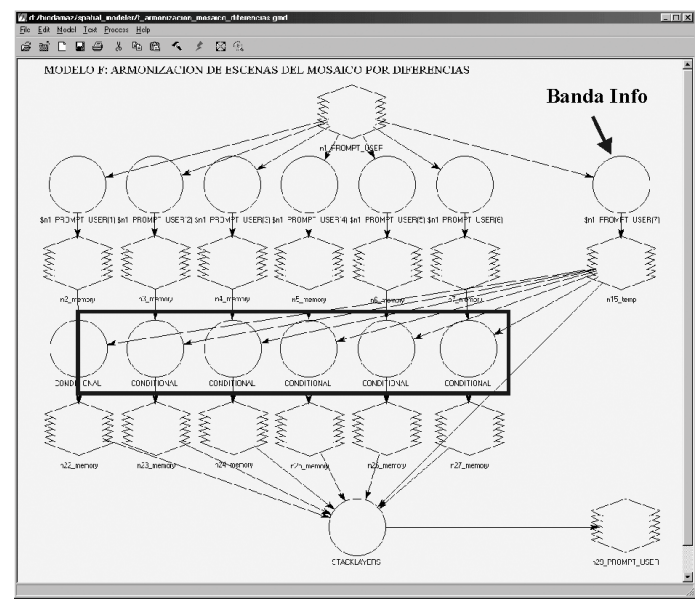

Figura 16. Modelo de armonización por diferencias.

Este proceso toma algunos minutos, o en todo caso algunas horas, dependiendo del tamaño del mosaico y de la capacidad del ordenador.

Después de comprobar los resultados obtenidos y determinar la correspondencia aceptable entre las escenas componentes del mosaico, se dio por finalizada esta fase.

Para el manejo del mosaico final fue necesario definir estrategias que nos permitan manipular la información de forma rápida y fácil; para esto fueron realizadas ventanas de corte, lo que nos permitió dividir el mosaico en 11 ventanas, guardando cada una la precisión del empalme.

Estas ventanas generadas nos facilitan el manipuleo del mosaico por sectores, pues dado el volumen de información que carga el mosaico (42 escenas), se presentó el inconveniente de manipular el mosaico en su totalidad.

\section{PRODUCTOS DEL MOSAICO}

Como productos principales del mosaico dentro del proyecto fueron considerados los siguientes:

a. Mapa de diversidad de vegetación: donde se expresa a la Amazonía peruana de selva baja como una compleja y variada cobertura vegetal con sus colores y tonalidades particulares, que corresponden a tipos de bosques y otras comunidades vegetales.

b. Mapa de unidades ambientales: expresa la diversidad de la Amazonía peruana en función de sus variables físicas (geología, geomorfología, hidrología y clima), y biológicas, (vegetación), lo cual ha permitido 
definir 21 espacios amazónicos. Estos espacios han sido denominados “unidades ambientales”, y servirán como patrones para la toma de decisiones sobre el manejo adecuado de los recursos del bosque y como herramienta eficaz para estudios específicos.

c. Apoyo a la Zonificación Ecológica Económica de la Amazonía peruana: los productos obtenidos servirán de apoyo para los estudios de Zonificación Ecológica Económica de la Amazonía peruana que es la herramienta para el proceso de ordenamiento territorial.

d. Mosaico y sus productos en el servidor del IIAP: estando en el servidor y a disposición de la comunidad nacional e internacional, el mosaico y sus productos contribuyen con un "granito de arena" al conocimiento de nuestra Amazonía de selva baja, al servicio de la comunidad científica, política y de usuarios en general. Se puede acceder a estos productos a través del Sistema de Información de la Diversidad Biológica y Ambiental de la Amazonía Peruana - SIAMAZONIA, www.siamazonia.org.pe

e. Mapa base (mosaico): servirá como herramienta base para otros estudios que se realicen.

\section{RESULTADOS Y DISCUSIÓN}

El objetivo principal del trabajo, que es la elaboración del mosaico que cubre la selva baja de la Amazonía peruana, se cumplió a cabalidad. También se ha generado productos a través de este mosaico, como el Mapa de Diversidad de Vegetación y el Mapa de Unidades Ambientales.

El presente mosaico está compuesto de 42 escenas de imágenes Landsat TM, las cuales fueron registradas entre los años 1980 y 2000.

Por otro lado, para elaborar un mosaico en la zona de selva baja es recomendable que las imágenes a ser integradas sean del mismo año, ya que nos permite tener una visión mucho más real del entorno, debido a que la dinámica fluvial en esta parte de la Amazonía es muy activa, pudiéndose modificar el paisaje en un tiempo muy corto.

El análisis visual de las imágenes para determinar su calidad es muy importante, porque nos permitió seleccionar aquellas imágenes no aptas para el proceso, ya sea por la distribución y/o presencia de nubes, ruidos u otras anomalías, permitiéndonos descartar algunas escenas para ser remplazadas por otras. Así mismo, fueron detectadas imágenes con márgenes no válidos, es decir, aquéllas que presentaban los valores digitales que superaban al máximo permitido $(255=$ color blanco $)$, los mismos que fueron corregidos con herramientas adecuadas del software, obteniéndose los valores del margen con cero (0).

Fueron restauradas líneas pérdidas en algunas imágenes, observándose que en el conjunto 'mayores de tres', la sustitución de los niveles digitales (NDs) no produce resultados satisfactorios, pues se generan amplias superficies con NDs uniformes. Este resultado era de esperar, puesto que el fenómeno de autocorrelación espacial en el que se sustenta el proceso de sustitución precisa que muchas variables tienden a presentar una fuerte asociación espacial; también señala que cuanto mayor es la distancia entre ellas, la asociación se reduce. Estas superficies no son significativas a pequeña escala, siendo más notorias a gran escala. Asimismo, es de presumir que al aplicarse procesos de clasificación multiespectral los resultados están fuertemente influenciados por estas áreas, debido a que estos procedimientos se apoyan en patrones de reflectancia para caracterizar las coberturas incluidas en la imagen.

También fueron georeferenciadas las imágenes, y para esto se utilizó las cartas nacionales como mapa de referencia a escala de 1:100 000. Se utilizó en algunos casos, cuando estuvieron disponibles, puntos claramente identificables en la imagen y en la carta, como los cruces de carretera, pistas de aterrizaje, edificaciones, etc.; es decir, aquellas referencias que tienen poca variabilidad en el tiempo. Sin embargo, en aquellas áreas en las que no existen esos tipos de referencia antes descritos se utilizo la red hídrica, aprovechando las confluencias entre los ríos y quebradas, con lo cual se obtuvo resultados satisfactorios. 
Las imágenes presentan un cambio gradual en los valores de los NDs, generalmente en dirección este a oeste, lo que es conocido como gradiente interna. Este fenómeno de gradiente se debe al efecto dispersor de la radiación electromagnética de los componentes de la atmósfera (aerosoles, vapor de agua, gases y otros). Esta anomalía es muy problemática cuando se quiere elaborar un mosaico de diferentes imágenes, por la gran variación que presenta cada una de ellas. Para corregir este efecto fue necesario recurrir a un modelo que midiese todas las variables físicas que causan este fenómeno. Para nuestro caso se utilizo la técnica de la interpolación proporcionada por el software ERDAS, que es una técnica "cosmética" ya que no considera el conocimiento profundo de los componentes físicos que ocasionan tal perturbación. Sin embargo, fueron generados diversos modelos que nos permitieron alcanzar resultados satisfactorios.

Se aplicó la técnica de armonización de los histogramas, con la finalidad de eliminar ciertas perturbaciones o desajustes presentes en las imágenes; luego, se elaboró el mosaico de imágenes, donde fueron ejecutados algunos procedimientos de corrección radiométrica, con la finalidad de mejorar la calidad, con lo que se obtuvo buenos resultados desde el punto de vista visual. Sin embargo, al realizar un realce al mosaico obtuvimos resultados no deseados. Deducimos que este efecto se debe a la diferencia radiométrica de los patrones de reflectancia de cada imagen, por la diferencia de fecha de adquisición de las mismas.

Finalmente, se puede decir que esta tecnología es muy eficiente como una herramienta complementaria para suministrar información en el proceso de conocer más el ambiente amazónico.

\section{AGRADECIMIENTOS}

Nuestro agradecimiento al proyecto BIODAMAZ, Perú - Finlandia, por la oportunidad de realizar este trabajo.

\section{BIBLIOGRAFÍA}

CHUVIECO, E. 1996. Fundamentos de Teledetección Espacial. Ediciones RIALP S.A. Madrid, España. 568 pp.

ELLIS, J.M.; DAVIS, H.; QUINN, M. 2001. Multiple applications for airborne hyperspectral sensors. Fifth International Conference on Airborne Remote Sensing, 17-20 September. URL:Ilwww.erin_int.com/ conf/5th-airborne/5thairborne.html.

ERDAS, INC. 1999. ERDAS IMAGINE Tour Guides. ERDAS IMAGINE V8.4. 5a. Edición. Atlanta, USA. $672 \mathrm{pp}$.

GONZALES, A. 1995. Aplicación de la Teledetección para la Fotointerpretación Preliminar de Unidades de Paisaje en Parque Natural Nacional de Paramillo. Rev. SIG-PAFC. No. 7, pág. 34-72.

KALLIOLA, R. 2001. Preprocesamiento de las imágenes Landsat TM para facilitar la creación de un mosaico a partir de ellas. Apéndice 4 del Informe de Consultoría, BIODAMAZ. Febrero-Abril de 2001. Universidad de Turku y Biota BD. BIODAMAZ, Perú - Finlandia, Iquitos, Perú. 20-28 pp.

MORELLA, A. 2002. Tecnología de Percepción Remota Hiperespectral en PDVSA como apoyo a la Definición del Sistema Petrolero y al Monitoreo Ambiental de Instalaciones. URL:Ilwww.asovig.org/documentos/ arrieche-m-hiperespectral.pdf

SIAMAZONIA - Sistema de Información de la Diversidad Biológica y Ambiental de la Amazonía Peruana. www.siamazonia.org.pe

TARAZONA, R. 1999. Deforestación en la Amazonía Peruana: causas, efectos, métodos de levantamiento y resultados. En: Monitoreo de la Deforestación y Zonificación Ecológica Económica en la Amazonía de Perú y Brasil. INRENA. Lima, Perú. 23-34 pp. 